\title{
Metodología de la investigación y cine comercial: claves de una experiencia docente
}

\author{
M.T. Icart-Isern ${ }^{a}, A C O P I^{b}$
}

Introducción. El cine se ha configurado, ya desde sus inicios, como una de las recreaciones humanas más extraordinarias que existen desde la perspectiva de la comunicación. Objetivo. El objetivo de este texto es presentar una experiencia docente en la que se empleó cine comercial (CC) en el desarrollo de la asignatura optativa 'Investigación en salud: métodos y técnicas', que se imparte en la Escuela de Enfermería de la Universitat de Barcelona. Desarrollo. Los contenidos de esta asignatura son los habituales en los cursos de investigación, y lo más interesante fue el empleo del CC, que se convirtió en el material (objeto) de estudio. En el transcurso de la asignatura, el alumno debía realizar una serie de actividades: revisión bibliográfica, preparación de un cuestionario, selección y visualización de una película de la que debía elaborar la correspondiente ficha técnica y un informe sobre los aspectos referidos a la enfermedad, el paciente, los profesionales y los valores, sentimientos y emociones asociados al problema de salud. Conclusiones. La experiencia puso de manifiesto la importancia de la observación atenta de las escenas para captar los mensajes no verbales relacionados con el problema de salud; la necesidad de adquirir habilidades para el manejo de las bases de datos bibliográficas (Medline, CINAHL, etc.), y la conveniencia de una mayor formación en el lenguaje cinematográfico para un mejor aprovechamiento didáctico del CC.

Palabras clave. Cine comercial. Cine educativo. Investigación. Metodología.

\section{Research methodology and commercial cinema: keys for an educational experience}

Introduction. The cinema has become from its beginnings, like one of the most extraordinary human recreation that exists from the communication point ofview. Aim. The objective of thispaper is to present an educational experience in which commercial cinema (CC) was used in the development of the optional subject 'Investigation in health: health research methods and techniques,' which is taught in the Nursing School at the University of Barcelona. Development. The content of the course is the common one for a research course being the most interesting thing the use of the CC that became the material (subject) of study. During the course, the students should carry out several activities: a literature review, to prepare a questionnaire, to select and visualize a movie of which the technical record and a report should be done. The report should consider aspects related to the illness, the patient, the professionals and the values, feelings and emotions associated to the health problem. Conclusions. The experience showed the importance of the attentive observation of the scenes to capture the non verbal messages related with the health problem; the need to get abilities for the handling of the bibliographical databases (Medline, CINAHL, etc.), and the convenience for more education to read the film language.

Key words. Commercial cinema. Educational cinema. Investigation. Methodology.

\section{Introducción}

Se reconoce que el cine es una de las recreaciones humanas más extraordinarias que existen desde la perspectiva de la comunicación. La información que codificamos gracias a las películas puede describir situaciones y generar emociones cuyo análisis es útil para provocar actitudes y conductas distintas a las habituales.

El empleo del cine comercial (CC) con propósito formativo cuenta con experiencias diversas en

\author{
a Escuela de Enfermería. \\ Universitat de Barcelona. \\ b Grupo de Innovación \\ Docente (A.M. Pulpón, \\ R. Álvarez, L. Barrachina, \\ R. Bernat, J. Colina, P. Isla, \\ V. SanFeliu). \\ Correspondencia \\ M. Teresa Icart Isern. \\ Escuela de Enfermería. \\ Universitat de Barcelona. \\ Feixa Llarga, s/n. E-08907 \\ L'Hospitalet de Llobregat \\ (Barcelona). \\ Fax \\ +34 934024297 \\ E-mail \\ mticart@ub.edu
}


los niveles educativos diferentes, que van desde la enseñanza primaria y secundaria, con un énfasis mayor en la educación en valores [1-4], hasta la universitaria, con aplicaciones específicas en carreras vinculadas a la salud, como medicina [5-8], biología [9], farmacia [10] o psicología [11].

El objetivo de este texto es presentar una experiencia docente en la que se empleó CC en la asignatura optativa 'Investigación en salud: métodos y técnicas' que se imparte en la Escuela de Enfermería de la Universitat de Barcelona.

\section{Del cine comercial al cine formativo}

Las posibilidades formativas del cine animaron a la creación de la Cinemateca Pedagógica (Ayuntamiento de París) y del Instituto Internacional de Cinematografía Educativa (Sociedad de Naciones, en Roma) [12] en la segunda década del siglo pasado. No obstante, hasta finalizada la Segunda Guerra Mundial no se contó con una oferta cinematográfica amplia procedente, principalmente, de EE. UU. y Europa. Este factor, unido al desarrollo de la tecnología audiovisual (televisión, vídeo, etc.) y a la incorporación a la industria del cine de Asia y Sudamérica, consolidó una nueva forma de consumir y producir cine.

En la última década del siglo $\mathrm{xx}$, el séptimo arte se populariza plenamente con avances tecnológicos como el home cinema, el DVD doméstico, la televisión digital, etc., factores que, con el fácil acceso al material (videoclubes, videotecas públicas, etc.) y la rápida comercialización (venta de películas en comercios especializados, pero también en kioscos y grandes superficies), convierten al cine en un medio de comunicación de masas [12].

El lenguaje cinematográfico cuenta con niveles distintos (Tabla I) [3,4] cuya identificación e interpretación son esenciales para comprender y disfrutar del cine. El primer nivel es el perceptivo (lo que se ve y se oye); el segundo corresponde a los lenguajes asociados (los referentes culturales), y el último y más complejo es el nivel subconsciente (las sensaciones y las emociones).

En efecto, la visualización de una película pone en marcha los sistemas perceptivos (vista y oído), a los que se suman otros lenguajes asociados, como la música y los efectos especiales, entre otros. Aún existe un tercer nivel que actúa de forma subconsciente, como la disposición de los encuadres, los movimientos de la cámara, la elección del espacio escénico, los movimientos de los actores, que representan otros aspectos que el espectador no suele percibir pero que combinados con los anteriores hacen del lenguaje cinematográfico uno de los más ricos y complejos. En el contexto educativo, el aprovechamiento del CC como recurso para la adquisición de conocimientos, habilidades y actitudes será óptimo si el docente y el discente conocen y comparten los códigos de este lenguaje.

Es importante que el estudiante sea consciente de que la película es un producto cuidadosamente planificado y realizado: nada o muy poco es fruto del azar. El buen cine se comporta como un manipulador perfecto que el buen espectador debe ser capaz de reconocer antes de sumergirse en su magia. Esto es así porque la apariencia de realidad se construye mediante ciertas convenciones invisibles para el espectador y que pueden convertirle en un consumidor pasivo e inconsciente [13].

Según de la Torre, catedrático de Didáctica e Innovación Educativa (Universitat de Barcelona), el cine formativo es 'la emisión y recepción intencional de películas portadoras de valores culturales, humanos, técnico-científicos o artísticos, con la finalidad de mejorar el conocimiento, las estrategias o las actitudes y opiniones de los espectadores'[12].

El carácter formativo de una película lo confiere su argumento, pero sobre todo la intencionalidad del docente que lo utiliza para promover la reflexión y el estudio de un tema o para estimular el análisis de un problema de salud. Este cine formativo se inscribe en un proceso dinámico que debe contar con la complicidad del docente y del alumno.

El proceso comienza con el empleo del CC, no concebido con fines pedagógicos, como un recurso adecuado para la enseñanza-aprendizaje de conocimientos y conductas deseables en los futuros profesionales de la salud. El docente es el encargado de iniciar esta transformación del CC con contenidos sobre salud, en material útil para impartir algunos temas de una asignatura; en otras palabras, debe planificar, organizar y evaluar el proceso. Esto exige un conocimiento adecuado de los contenidos de la materia y del recurso, la habilidad para preparar actividades y materiales que conecten a los anteriores y, cómo no, el gusto por el séptimo arte, algo que se puede transmitir a los alumnos y que tal vez perdure tras su paso por las aulas. Por otra parte, el alumno universitario cuenta con una formación y experiencia cinematográfi- 
Tabla I. Niveles de comunicación a través del cine.

\section{Nivel 1}

Nivel de los sistemas perceptivos (vista y oído). Se accede a este nivel a través de los estímulos primarios: líneas, colores, sonidos, etc. Se obtiene la configuración sensible de la imagen

\section{Nivel 2}

Nivel de los lenguajes asociados a los sistemas perceptivos: imagen, sonido fonético, sonido musical, ruidos y señales. Se obtienen los referentes culturales de reconocimiento y codificación

\section{Nivel 3}

Nivel subconsciente: disposición de los encuadres, los movimientos de cámara, la elección del espacio escénico, la elección de la música y el movimiento de los actores. Se transmiten sensaciones y emociones

cas variables, al igual que lo son sus conocimientos sobre los contenidos de la carrera, estos factores condicionan el aprovechamiento y sus resultados finales, tanto cognitivos como emocionales.

En España, el uso académico del CC con contenidos médico-científicos cuenta con experiencias diversas. La Facultad de Medicina de la Universidad de Salamanca es la más veterana y pionera en la difusión de las posibilidades del binomio Medicina y Cine, título de la excelente revista en línea (y gratuita) que publica desde enero de $2005[14,15]$.

\section{Relato de una experiencia: investigación y cine comercial}

La experiencia que sigue nació de la voluntad de conciliar filias y fobias o el cine y la investigación; así surgió la asignatura 'Investigación en salud: métodos y técnicas' (a través del cine) (tres créditos), que empezó a impartirse en la Escuela de Enfermería (Universitat de Barcelona), en septiembre de 2006.

Se trata de una asignatura que se ofrece a partir del tercer semestre con el requisito previo de haber superado, entre otras, la troncal de Enfermería Comunitaria I (segundo semestre), ya que el conocimiento del Método Epidemiológico y de la Bioestadística facilitan la comprensión de los métodos y las técnicas de investigación.

Los objetivos de la asignatura, que para la mayoría de matriculados supone su primer contacto con la investigación universitaria, son que el alumno/a:

- Comprenda y analice las etapas de la investigación, las actividades y los recursos necesarios para cada una de ellas.

- Aprenda a utilizar con eficiencia algunas de las bases de datos bibliográficas más importantes en salud.

- Desarrolle y aplique el proceso de la investigación con el empleo de los recursos que ofrece el CC con contenidos sobre salud.

Los contenidos de la asignatura optativa son los habituales en los cursos de investigación (Tabla II), y lo más interesante es su aplicación al $\mathrm{CC}$, que se convierte así en material (objeto/sujeto) de estudio.

La propuesta de maridaje entre investigación y cine fue muy bien recibida por los 20 matriculados (número máximo permitido), cuya mayoría reconoció estar en el curso por conveniencia horaria o para sumar tres créditos en su expediente.

Las exposiciones teóricas referidas a los diseños clínico-epidemiológicos, los métodos cualitativos (fenomenología, etnografía, documentación, etc.), la selección de los participantes, la obtención y el análisis de los datos fueron intencionadamente breves y reforzados con la entrega de varios documentos sobre metodología.

Con voluntad cómplice entre docente y alumnos se seleccionó el tema y se formuló el objetivo principal (Tabla II) que posteriormente se revisó.

En cuanto a las actividades, la primera fue de autoaprendizaje (Tabla III) y consistió en la búsqueda bibliográfica en bases especializadas en medicina (Medline e IME), en enfermería (CINAHL y CUIDEN) y en cine [16], de dos documentos por alumno sobre salud (enfermedad/medicina/ enfermería) y cine.

Además, todos debían ver la película Philadelphia, que fue elegida por su accesibilidad (disponible en videoclubes y en videotecas públicas), actualidad de la enfermedad (sida) y por contar con un artículo en la revista Medicina y Cine [17], 
Tabla II. Contenidos del programa de la asignatura optativa 'Investigación en salud: métodos y técnicas' y su aplicación en el cine comercial.

Etapas de la investigación

Aplicación en el cine comercial

Selección del tema

Enfermedad en el cine comercial

Revisión bibliográfica

Bases de datos de medicina, enfermería y cine

Formulación del objetivo de investigación

Describir el abordaje/tratamiento de problemas de salud en las películas (disponibles en DVD) producidas en los últimos 30 años

Selección del diseño

Descriptivo y transversal

Material estudiado: criterios de inclusión/exclusión y técnicas de selección

Películas en DVD en cuyos guiones se considera un problema de salud o enfermedad. Se excluyen las películas de animación y las no dobladas al castellano. Técnica de selección: no probabilística, de conveniencia

Variables que se deben estudiar

Enfermedad/es. Aparatos o sistemas implicados. Fase de la enfermedad. Profesionales implicados. Variables epidemiológicas del enfermo. Valores, emociones, sentimientos asociados a la enfermedad

\section{Obtención de datos}

Elaboración de la ficha técnica y de una hoja de registro con preguntas cerradas y abiertas que hay que responder mediante la visualización de la película

\section{Análisis de datos}

Codificación y análisis descriptivo de las variables

Comunicación de resultados

Presentación del informe y de la ficha técnica

que podía ejemplificar esa otra forma de valorar y analizar una película.

Los aspectos diferentes (variables) que presenta Philadelphia serían los que servirían de base a la actividad siguiente: la preparación de un
Tabla III. Actividades de autoaprendizaje desarrolladas durante la asignatura optativa.

- Revisión bibliográfica y obtención de dos documentos por alumno

- Visualización individualizada de la película Philadelphia

- Preparación de un cuestionario con 8-10 preguntas abiertas y cerradas

- Discusión y consenso del cuestionario final que serviría de base para la redacción del informe

- Selección de una película por parte de cada alumno

- Visualización de la película seleccionada. Realización y presentación escrita de la ficha técnica y el informe correspondientes

- Entrega de la ficha técnica y el informe de la película seleccionada

- Comentarios y valoración global de los informes

- Evaluación escrita de la asignatura

- Publicación de calificaciones en un dossier electrónico

cuestionario mixto (de 8 a 10 preguntas) sobre variables que, potencialmente, estarían presentes en cualquier película con contenidos sobre salud (enfermedad, paciente, profesionales, entorno sociosanitario, valores/creencias, etc.).

La siguiente actividad fue la selección por parte de cada alumno de una película con contenidos sobre salud. A partir de la película elegida se elaboró la ficha técnica (título original, nacionalidad, año, director, guionista, música, intérpretes, duración, género, productor y sinopsis) y se redactó un informe que analizaba la enfermedad o el problema de salud desde perspectivas distintas, también se exigía la descripción de las secuencias (identificadas en minutos) en las que éste aparecía. El informe (tres a cuatro páginas) debía incluir de cuatro a siete referencias bibliográficas de distinta procedencia (Medline, prensa e internet).

Este informe, junto al resto de actividades y la participación en clase, permitieron la evaluación. Se evaluó de forma positiva la cumplimentación correcta de la ficha técnica. Respecto al informe, el alumno debía detallar el contenido de los diálogos y las imágenes relacionadas con el problema de salud; las referencias debían seguir la normativa Vancouver y contener en su título, la enfermedad mencionada en la película. 
El último día de clase sirvió para comentar los puntos fuertes y débiles de los informes ya entregados; las calificaciones se publicaron en el dossier electrónico dos días más tarde. Además, los alumnos evaluaron la asignatura con la respuesta, de forma anónima, a un cuestionario estándar (calidad de los contenidos, documentación recibida, docencia, etc.); la puntuación global otorgada a la asignatura fue de 3,6 sobre 4 . En las preguntas abiertas, uno de los comentarios más reiterados indicaba que a raíz de la asignatura optativa observarían y mirarían el cine de otra manera, 'con otros ojos' ; se fijarían más en los aspectos de salud, analizarían los temas médicos y el papel de los profesionales con más atención, etc.

Los resultados de aprendizaje esperados en los estudiantes eran que éstos conocieran las actividades propias de la investigación, los recursos que ofrece la base bibliográfica Medline, y que comprendieran que los temas objeto de estudio pueden ser diversos y hasta entretenidos. Las calificaciones obtenidas por los alumnos fueron: 3 aprobados, 11 notables, 5 sobresalientes y 1 matrícula.

Naturalmente, es una experiencia insuficiente para evaluar el impacto o la utilidad que puede tener el uso del CC en el aprendizaje y la asimilación de la asignatura 'Investigación en salud: métodos y técnicas', pero es innegable que se trata de una experiencia que ha conseguido implicar a los alumnos en unos contenidos, los de investigación, que con frecuencia consideran 'cuestión de otros'.

\section{Conclusiones}

La experiencia descrita es un ejemplo del uso del $\mathrm{CC}$ en la docencia y sirve para ilustrar que la intencionalidad es esencial [12] cuando se trata de aprovechar un recurso, el cine, para reforzar unos conocimientos aparentemente inconexos como son los de la metodología de la investigación.

En cuanto a las limitaciones o debilidades de la experiencia, los alumnos destacaron la dificultad para realizar una lectura en profundidad de las imágenes, lo que atribuyeron a su falta de cultura cinematográfica [13]; se trata de una situación que Stahelim resume cuando afirma: '... así como hay que aprender a leer, también hay que aprender a ver cine. Y si leer no es deletrear, ver cine no es mirar a la pantalla durante la proyección' (citado por Pereira MC [18]). Aunque conocer los pormenores del análisis cinematográfico no es un objetivo de la asignatura, como tampoco lo es el dominio de la comunicación oral y escrita de la investigación ni contar con un buen conocimiento del inglés, nadie duda de que son competencias transversales y muy valiosas en la era de la comunicación.

Sin pretender que la asignatura se convierta en la excusa para un cine-forum, sí que se deberían articular estrategias para favorecer el debate, la exposición de diferentes puntos de vista e incluso, en algunos casos, la capacidad para identificar posibles puntos de coincidencia. Estas habilidades son útiles en las reuniones de consenso y en la toma de decisiones en las que participará el futuro profesional.

Otras cuestiones susceptibles de mejora se refieren a la concreción y especificidad de los objetivos del proyecto (Tabla II) que, como era previsible, se revelaron demasiado generales. Por esta razón, en los cursos siguientes de la asignatura optativa se ha concretado la patología (cáncer para un grupo y enfermedades cardiovasculares para el otro) que tendrán que abordar las películas analizadas por los alumnos.

Entre las fortalezas de la experiencia, los alumnos reconocieron la importancia de la observación y del análisis de las imágenes y de lo no verbal. Esto reviste gran interés, ya que una de las competencias exigibles a los futuros profesionales es su capacidad para una escucha atenta del paciente y para reconocer los mensajes que destila su comunicación no verbal.

En este sentido, el informe recogía la valoración de todos los detalles presentes en las escenas referidas a la enfermedad y de las que debían extraer todo tipo de datos. En último término, fijar la atención en el paciente, en lo que dice y en lo que calla, es un objetivo deseable en el encuentro clínico.

Es obvio que existen diferencias entre el análisis de secuencias cinematográficas y la realidad de este encuentro, porque los componentes de los niveles de lenguaje asociado a los sistemas perceptivo y subconsciente son diferentes (la vida real no se acompaña de banda sonora), pero en ambos casos es primordial reconocer los referentes culturales, así como las sensaciones y emociones que retrotraen esos niveles y que tienen como protagonistas tanto al paciente como al propio profesional.

Otra fortaleza de la experiencia es la secuenciación de teoría sobre investigación y su aplicación práctica. Aunque es mejorable, los alumnos consideraron que las exposiciones sobre metodología y las actividades relativas al CC se potenciaban y 
enriquecían mutuamente, así que finalmente se impuso la filia sobre la fobia.

Otro punto fuerte y muy bien valorado fue el esfuerzo destinado a la búsqueda bibliográfica que obligó a los alumnos a explorar diferentes tipos de bases documentales, desde las más ortodoxas en salud (Medline, CINAHL, etc.) hasta las más informales (blogdecine); dicho esfuerzo prueba la identificación de los documentos aportados tras la búsqueda y las referencias bibliográficas de los informes; al respecto, destaca su calidad y la descripción minuciosa de algunas escenas.

Estimo que es una forma 'suave', si se quiere light, de abordar la metodología de la investigación que en general resulta lejana a los intereses formativos inmediatos de los matriculados en enfermería: la mayoría contempla la investigación como una actividad al margen de su futuro trabajo asistencial; apreciación que no creo muy diferente entre los estudiantes de los primeros cursos de medicina, farmacia o psicología.

Sin embargo, todos están familiarizados, en mayor o menor medida, con la gran (y pequeña) pantalla, ya que han nacido en un mundo audiovisual en el que el cine les brinda la oportunidad de vivir ricamente situaciones y emociones en muchos casos similares a las que ocurren en la realidad [13]. Ésta es una de las virtudes del cine que a través de los diálogos y las imágenes en movimiento transmite información a la vez que potencia emociones en el espectador.

Finalmente, cabe reconocer que el empleo del cine en el aprendizaje-enseñanza de contenidos académicos representa un sistema de comunicación que integra la observación, la reflexión y el análisis de conocimientos y actitudes; su extraordinaria potencialidad la podría resumir la frase de Eric Rohmer: 'El cine es pedagogía a 24 imágenes por segundo'.

\section{Bibliografía}

1. Álvarez D, Cariacedo JJ, Gómez JM, López S, Peña JI, Pereda FJ, et al. El valor de la diversidad. El cine como recurso didáctico en la educación intercultural. Madrid: Carprinter; 2003.

2. Martínez J (coord.). Películas para usar en el aula. Madrid: UNED; 2006.
3. Pereira MC, Urpí MC. Cine y juventud: una propuesta educativa integral. Revista de Estudios de Juventud 2005; 68: 73-80.

4. Pereira MC, Urpí MC. El cine en la escuela informal de nuestra juventud. Cuadernos de Cine y Educación 2004; 28: 233-55.

5. Menéndez A, Medina RM. Cine, historia y medicina. Suplemento de Conecta n. ${ }^{\circ} 1 ; 2003$. URL: http://www.dsp. umh.es/conecta/cmh/Cine.pdf. [13.12.2006].

6. García-Sánchez JE, Frenadillo MJ, García-Sánchez E. El cine en la docencia de las enfermedades infecciosas y la microbiología clínica. Enferm Infecc Microbiol Clin 2002; 20: 403-6.

7. Loscos J, Baños JE, Loscos F, De la Cámara J. Medicina, cine y literatura: una experiencia docente en la Universidad Autónoma de Barcelona. Revista de Medicina y Cine 2006; 4: 1-7. URL: http://www.usal.es/ revistamedicinacine. [13.12.2006].

8. González-Blasco P, Roncoletta AFT, Moreto G, Levites MR, Janaudis MA. Medicina de familia y cine: un recurso humanístico para educar la afectividad. Aten Primaria 2005; 36: 566-72.

9. Baños JE, Aramburu JF, Sentí M. Biocinema: la experiencia de emplear películas comerciales con estudiantes de biología. Revista de Medicina y Cine 2005. URL: http:// www.usal.es/ revistamedicinacine. [20.07.2006].

10. Bosch F, Baños JE. Empleo de películas comerciales en la docencia de la farmacología. Educ Med 1999; 4; 197.

11. Alexander M, May MN, Pettice YJ. Cinemeducation: an innovative approach to teaching psychosocial medical care. Fam Med 1994; 26: 430-3.

12. De la Torre S. Cine formativo. Una estrategia innovadora para los docentes. Barcelona: Octaedro; 1997.

13. Aguilar P. Manual del espectador inteligente. Madrid: Fundamentos; 1996.

14. López A. Aprender del cine. URL: http://elmundosalud. elmundo.es/elmundosalud/2005/02/18. [10.07.2006].

15. García JE, Trujillano I, García E. Medicina y cine. ¿Por qué? [editorial]. Revista de Medicina y Cine 2005; 1. URL: http://www.usal.es/ revistamedicinacine/indice_2005/ Revista/numero_1. [25.10.2006].

16. Martínez-Salanova E. Cine y educación. Huelva. URL: http://www.uhu.es/cine.educacion/cineyeducación/enlaces.htm. [10.07.2006].

17. Aijón J. Philadelphia (1993): las claves de un icono cultural. Revista de Medicina y Cine 2005; 1. URL: http:// www.usal.es/ revistamedicinacine/indice_2005/Revista/ numero_4. [20.07.2006].

18. Pereira MC. El cine, nuevo escenario de la educación. In Romaña MT, Martínez M, eds. Otros lenguajes en educación. Barcelona: ICE-Universidad de Barcelona; 2003. p. 101-5. 